\title{
Atrichia with Papular Lesions: Importance of Histology at an Early Disease Stage
}

\author{
Vanessa B. Rocha $^{a}$ Nilceo Michalany ${ }^{b}$ Neusa Y.S. Valente ${ }^{c}$ Luciana B. Pereira $^{d}$ \\ Aline Donati ${ }^{\mathrm{a}}$ \\ ${ }^{a}$ Department of Dermatology, Hospital do Servidor Público Municipal, ${ }^{b}$ Department of Dermatology, Federal \\ University of São Paulo, and ' Department of Dermatology, University of São Paulo, São Paulo, and d Department of \\ Dermatology, Hospital das Clínicas da UFMG, Belo Horizonte, Brazil
}

\section{Keywords}

Alopecia · Dermatopathology $\cdot$ Histopathological examination

\begin{abstract}
We report the case of a 5-year-old girl born from consanguineous parents, presenting with alopecia universalis since the age of 8 months, without papules or cysts over the scalp or body. The goal of this paper is to emphasize the relevance of histopathology for the early diagnosis of atrichia with papular lesions in children with alopecia universalis, in settings where genetic testing may not be available.
\end{abstract}

(c) 2017 S. Karger AG, Basel

Alopecia universalis (AU) is a heterogeneous group of disorders with complete or almost complete loss of scalp and body hair. The most frequent cause of AU is alopecia areata, but genetic conditions must be taken into account, especially in pediatric cases [1].

We report the case of a 5 -year-old girl born from consanguineous parents, presenting with $\mathrm{AU}$ since the age of 8 months (Fig. 1a). No papules or cysts were detected at first consultation over the scalp or body (Fig. 1b), and scalp dermoscopy revealed evenly distributed clusters of follicular openings (Fig. 1c). The girl's growth and neurologic development were normal, as well as her adnexal structures and bones. There had been no previous treatments. Differential diagnosis included alopecia areata, atrichia with papular lesions (APL), and hypotrichosis congenita simplex [1]. After parental consent, scalp biopsy was performed at the crown region after local anesthesia. The patient tolerated the procedure well. Histopathology showed no terminal hair follicles and no peribulbar infiltrate but several keratin cysts (Fig. 1d), confirming the diagnosis of APL [1].

APL is a rare autosomal recessive follicular disorder caused by nonsense mutations of the hairless (HR) gene (OMIM 209500) $[1,2]$. Lanugo hairs are present at birth but alopecia is complete within the first year of life as catagen follicles are unable to re-enter the anagen phase. Progressive keratin retention into follicular structures results in cystic formations clinically evident as papules [3], a hallmark of the disease. Differential diagnosis of alopecia areata before the appearance of papules is challenging and relies mostly on genetic testing $[1,2,4]$.

Consanguinity is an important clue and should always be investigated in pediatric cases. The development of AU within the first year of life, disseminated cysts or papules and nonresponsiveness to therapy all together strongly suggest the diagnosis of APL, but the detection of HR mutations is the gold standard for the diagnosis [3].

\section{KARGER}

(c) 2017 S. Karger AG, Basel

E-Mail karger@karger.com

www.karger.com/sad
Vanessa Barreto Rocha

Contorno av, 9681 sl 403

Belo Horizonte, MG 30110-063 (Brazil)

E-Mail vanessabarreto@ oi.com.br 

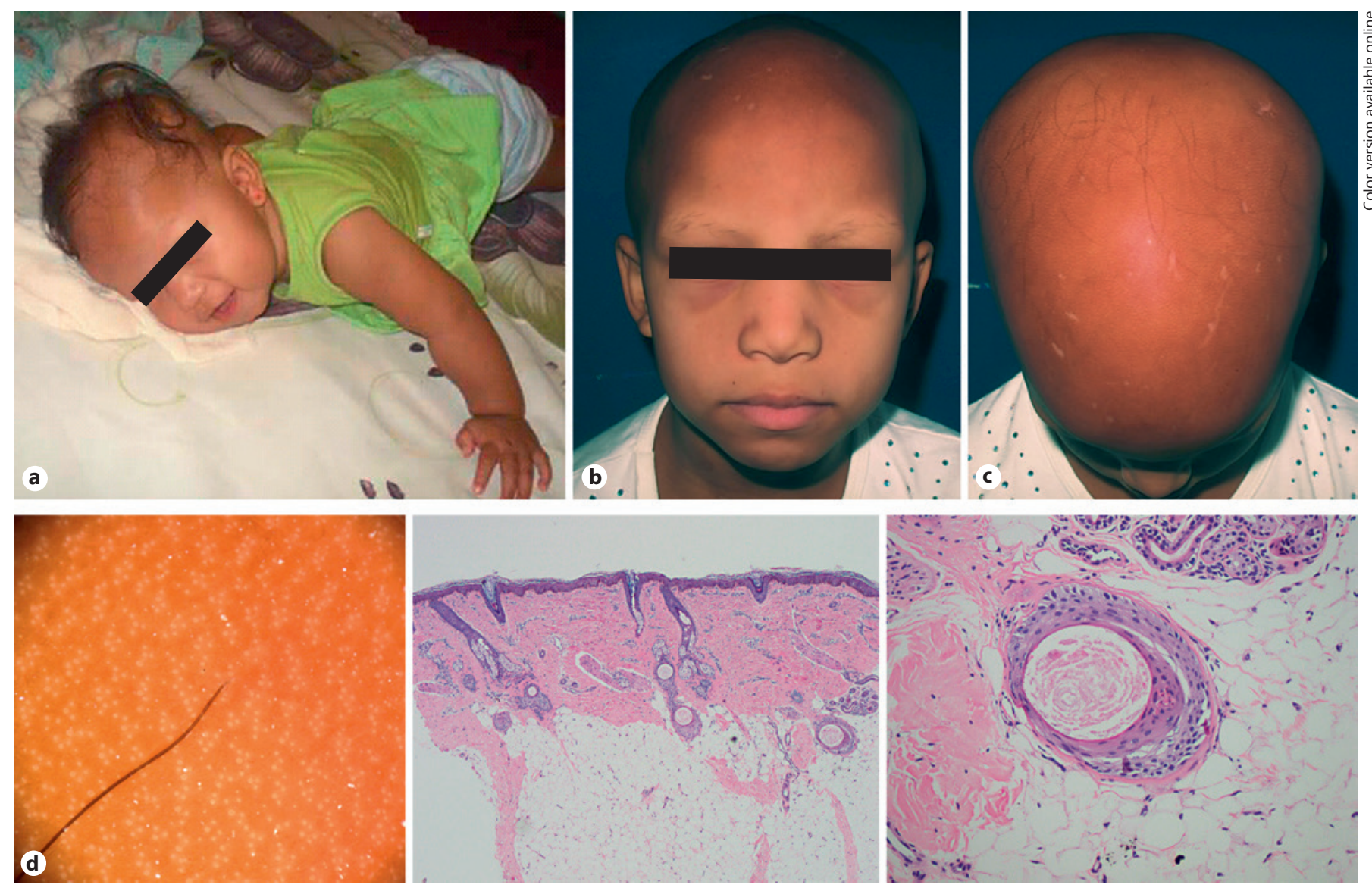

Fig. 1. a Alopecia universalis in the patient at the age of 8 months (photos taken by the girl's mother). b Clinical presentation at the age of 5 years. $\mathbf{c}$ No papules or cysts are present, and scalp dermoscopy reveals evenly distributed clusters of follicular openings. d Scalp biopsies with no terminal hair follicles, but several keratin cysts. HE. $\times 40$ and $\times 400$.

Since genetic testing is not available in many health care settings, histopathology may be relevant for the early diagnosis of APL in children with AU, as demonstrated in our case. Histopathological examination can reveal small follicular cysts not yet detectable on physical examination. Even though it may be more difficult to perform a scalp biopsy in children [3], the procedure can be safely performed and should be offered whenever genetic testing is not available in order to avoid unnecessary and potentially harmful treatments [1].

\section{Statement of Ethics}

This is a case report and parental consent has been obtained both for report and pictures. Confidentiality and anonymity of the patient is ensured and authors have no conflict of interest to declare.

\section{Disclosure Statement}

The authors have no conflicts of interest to disclose.

\section{References}

1 Zlotogorski A, Panteleyev AA, Aita VM, Christiano AM: Clinical and molecular diagnostic criteria of congenital atrichia with papular lesions. J Invest Dermatol 2002;118:887-890.

2 Henn W, Zlotogorski A, Lam H, Martinez-Mir A, Zaun H, Christiano AM: Atrichia with papular lesions resulting from compound heterozygous mutations in the hairless gene: a lesson for differential diagnosis of alopecia universalis. J Am Acad Dermatol 2002;47:519-523.

3 Yip L, Horev L, Sinclair R, Zlotogorski A: Atrichia with papular lesions: a report of three novel human hairless gene mutations and a revision of diagnostic criteria. Acta Derm Venereol 2008;88:346-349.

4 Bennàssar $\mathrm{A}$, Ferrando J, Grimalt R: Congenital atrichia and hypotrichosis. World J Pediatr 2011;7:111-117. 